\title{
Bridging the gap: creating a self-sustaining neurosurgical residency program in Haiti
}

\author{
Ashish H. Shah, MD, ${ }^{1}$ Ernest Barthélemy, MD, ${ }^{3,4}$ Yudy Lafortune, MD, ${ }^{5}$ Joanna Gernsback, MD, \\ Ariel Henry, MD, ${ }^{5}$ Barth Green, MD, ${ }^{1}$ and John Ragheb, MD ${ }^{1,2}$

\begin{abstract}
1Department of Neurosurgery, University of Miami; 2 Division of Neurosurgery, Nicklaus Children's Hospital, Miami, Florida; ${ }^{3}$ Department of Neurosurgery, Mt. Sinai Hospital, New York, New York; ${ }^{4}$ Department of Global Health and Social Medicine/ Program in Global Surgery and Social Change, Harvard Medical School, Boston, Massachusetts; and ${ }^{5}$ Department of Neurological Surgery, Hospital Bernard-Mevs/Project Medishare, Port-au-Prince, Haiti
\end{abstract}

Given Haiti's longstanding socioeconomic burden and recent environmental and epidemiological catastrophes, the capacity for neurosurgery within Haiti has been limited, and outcomes for patients with neurosurgical conditions have remained poor. With few formally trained neurosurgeons (4) in a country of 10.5 million inhabitants, there is a significant need for the development of formal structured neurosurgical training. To mitigate the lack of neurosurgical care within Haiti, the authors established the first neurosurgical residency program within the country by creating an integrated model that uniquely fortifies existing Haitian neurosurgery with government sponsorship (Haitian Ministry of Health and National Medical School) and continual foreign support. By incorporating web-based learning modules, online assessments, teleconferences, and visiting professorships, the residency aims to train neurosurgeons over the course of 3-5 years to meet the healthcare needs of the nation. Although in its infancy, this model aims to facilitate neurosurgical capacity building by ultimately creating a self-sustaining residency program.

https://thejns.org/doi/abs/10.3171/2018.7.FOCUS18279

KEYWORDS Haiti; neurosurgery; sustainable; teaching; global health

$\mathrm{T}$ HE global burden of neurosurgical disease has been vastly underestimated as a major contributor to public health morbidity. In 2010, surgically treatable conditions contributed to nearly one-third of all deaths worldwide (16.9 million), with more than 5 billion people lacking access to timely, safe, affordable surgical care. ${ }^{8,10}$ The inequity is especially pronounced in low- and middleincome countries (LMICs), where the vast majority of patients cannot afford access to surgical or anesthesia care. In LMICs such as Haiti, Uganda, Sierra Leone, etc., surgically treatable diseases may remain untreated in up to $25 \%$ of the population and account for at least $70 \%$ of the global burden of deaths from these conditions. ${ }^{6,11}$ This global inequity is even more pronounced in areas of specialty surgical care such as neurosurgery, particularly pediatric neurosurgery (large disease burden necessitating highly specialized skill set), for which the capacity for care delivery in LMICs can range from being sparse to completely absent. ${ }^{9}$ In Haiti, where access is limited for emergency or necessary surgeries, the concept of neurosurgery in particular has been relatively neglected as a subspecialty. ${ }^{4}$ Given Haiti's longstanding socioeconomic burden and postcolonial legacy as the "poorest nation in the Western Hemisphere," and given recent environmental and epidemiological catastrophes (2010 earthquake, Hurricane Matthew, cholera epidemic), neurosurgical capacity is limited and outcomes for neurosurgical conditions have remained poor. ${ }^{1,5}$

Over the last 3 decades, many factors have contributed to the disparity in neurosurgical care within the country of Haiti. Excessive urban population density, rising rates of rural-to-urban migration, and an estimated $10 \%$ annual growth rate of motorized transportation all contribute to the growing number of patients requiring emergency neurosurgical care. ${ }^{12}$ However, the burden of neurosurgical

ABBREVIATIONS CCHU = CURE Children's Hospital of Uganda; ER = emergency room; FIENS = Foundation for International Education in Neurological Surgery; HBMPM = Hospital Bernard-Mevs/Project Medishare; HIC = high-income country; HUEH = Hôpital Université d'État d'Haïti; LMICs = low- and middle-income countries.

SUBMITTED May 31, 2018. ACCEPTED July 11, 2018.

INCLUDE WHEN CITING DOI: 10.3171/2018.7.FOCUS18279. 
disease within the country has not been well characterized. Currently, cerebrovascular disease and neurotrauma remain the leading contributors to emergency neurological disease in Haiti, accounting for more than $15 \%$ of all

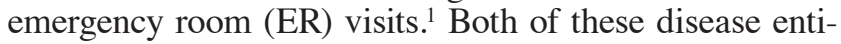
ties significantly contribute to surgically preventable disability and mortality in Haiti. Although the Centers for Disease Control (CDC) estimate that the US has a similar neurological disease burden, the cumulative effect of Haiti's onerous economic challenges, lack of disease prevention, limited availability of modern equipment (implants, advanced imaging, instrumentation, etc.), and poor healthcare access exacerbates outcomes for patients with potentially treatable neurological conditions.

Currently, Haiti has very few formally trained neurosurgeons (4) for a population of 10.5 million inhabitants, which severely impairs healthcare access. Furthermore, formal neurosurgical training may be variable: on one hand, neurosurgeons may have received training in France, whereas others have participated in observerships in neighboring French islands (e.g., Martinique). Currently, the neurosurgeon provider ratio per 100,000 people is approximately 0.04 (more than 20 -fold less than that of developed countries like the US). ${ }^{1,14}$ With no structured neurosurgical care outside of the capital, Port-au-Prince, there is a significant need within the country for the development of formal neurosurgical training.

\section{Neurosurgical Disease Burden}

In order to estimate the need for neurosurgical training, an appraisal of the neurosurgical disease burden would be necessary. Prior to the earthquake in 2010, a formal estimate of the neurosurgical disease burden within Haiti was not possible. Haiti had no formal system of surveying neurosurgical injuries or diseases in its fragmented hospital systems. To date, few studies have been conducted on the epidemiology of neurosurgical disease within the country. Since the earthquake and the establishment of a dedicated trauma hospital (Hospital Bernard-Mevs/Project Medishare [HBMPM], Port-au-Prince, Haiti), an accurate accounting of neurosurgical disease has become more feasible. With more than 200 trauma patients per month, HBMPM serves a unique role as a trauma center in Haiti, with a significant proportion of the country's neurosurgical disease. ${ }^{15}$ Many of the demographic trends and factors described above have contributed, during the past 3 decades, to a growing number of neurosurgical patients presenting at HBMPM with traumatic injuries of the nervous system. Indeed, it is estimated that nearly $20 \%$ of all neurological visits in the ER (approximately 3\%-5\% of all ER visits) require neurosurgical evaluation. ${ }^{1}$ Of all cases requiring surgery, approximately $3 \%$ required neurosur- gery (this figure was as high as 5\% immediately after the earthquake). ${ }^{2}$ However, these estimates fail to account for elective neurosurgical cases such as pediatric postinfectious hydrocephalus, brain tumors, spinal deformity, etc. Given the current size of the population and these estimates, it is projected that the country would need at least 10-15 neurosurgeons distributed throughout the country to provide adequate neurosurgical care.

\section{Models of Training Programs}

Over the past 20 years, several models of educational and training partnership have emerged to address the critical shortage of neurosurgeons in LMICs. While the success of each relies on the concerted effort of multiple partners, each paradigm offers distinct benefits and challenges that are worthy of consideration. These programs will be briefly described here to contextualize the model we have developed in Haiti. These training models may be thought of as belonging to 1 of 3 different paradigms: 1) creation of nongovernmental, private training programs, 2) expansion of existing local training programs, and 3) creation of government-sponsored public-private training programs (Table 1).

\section{Creation of Nongovernmental, Private Training Programs}

One possible training paradigm for expanding the neurosurgical workforce of LMICs is the creation of a new private training program or initiative in a state-of-the-art facility. This approach may be particularly appropriate when there is no existing local institution or framework delivering the type of training in question. Benefits of this approach include maximum freedom in the design and implementation of the initiative and, when done in a culturally sensitive and socially effective manner, it can provide transformative and enduring solutions to problems of inequity in access to specialty surgical care. Challenges in this approach include the highest start-up and operating costs of all models, and the risk of untoward effects on the local healthcare ecosystem, such as diverting patient care away from existing facilities that serve the same population. The experience of Dr. Benjamin Warf and the CURE Children's Hospital of Uganda (CCHU) is one example of effective implementation of this strategy. CCHU has been treating children with hydrocephalus since 2001 and, with support from a grant awarded by the Foundation for International Education in Neurological Surgery (FIENS), CCHU's International Program to Advance the Treatment of Hydrocephalus trains and equips local and visiting neurosurgeons from LMICs in the technique of endoscopic third ventriculostomy and choroid plexus cauterization. ${ }^{13}$ Currently, besides an American administrator from CURE International, CCHU is entirely staffed by Ugandans.?

TABLE 1. Neurosurgery training paradigms in LMICs

\begin{tabular}{|c|c|c|}
\hline Category 1 & Category 2 & Category 3 \\
\hline $\begin{array}{l}\text { Creation of nongovernmental, private training programs } \\
\text { (e.g., CCHU International Program to Advance the } \\
\text { Treatment of Hydrocephalus) }\end{array}$ & $\begin{array}{l}\text { Expansion of existing private training programs } \\
\text { (e.g., East African Neurosurgery Training } \\
\text { Program) }\end{array}$ & $\begin{array}{l}\text { Creation of government-sponsored } \\
\text { public-private training programs (e.g., } \\
\text { Madaktari Africa) }\end{array}$ \\
\hline
\end{tabular}




\section{Expansion of Existing Private Training Programs}

Another paradigm for neurosurgical workforce development in LMICs is to leverage an existing program at a private facility and expand it through academic twinning with a high-income country (HIC) partner. This approach takes advantage of existing infrastructure and local systems that can facilitate program development. Benefits of this approach include lower start-up costs than those associated with a brand new facility; an opportunity to directly empower an existing local system; and engagement of local program providers, educators, and leadership. Possible challenges of this approach include limitations of local facilities and equipment, and cultural, design, or logistical constraints on the ambition of HIC partners. This approach is exemplified by the efforts of the Duke University Neurosurgery Training Program's partnership with the Department of Neurosurgery at Mulago Hospital in Uganda, an effort spearheaded by the collaborative work of the respective directors of these institutions: Drs. Michael Haglund and Michael Muhuzuma. In 2009, the first 2 Ugandan residents were accepted into the East African Neurosurgery Training Program, a fellowship of the College of Surgeons of Eastern, Central, and Southern Africa (COSECSA) supported by FIENS. The program aims to increase the number of practicing Ugandan neurosurgeons from 5 to 22 by the year 2022 ?

\section{Creation of Government-Sponsored Public-Private Training Programs}

A third paradigm for developing the neurosurgical workforce of LMICs is to integrate a new training program into a government-sponsored HIC-LMIC twinning agreement. This approach is distinct from those mentioned above in that it enlists local governance to develop a residency or fellowship where no prior training program was in place, and it is the approach we have used for the program in Haiti described below. In addition to the benefits of leveraging existing resources, this paradigm directly engages local political stakeholders and frameworks for graduate medical education, which can facilitate autonomy in program development, and ultimately complete transference of the new training program to the LMIC partner. Challenges may include delays in implementation related to bureaucratic processes, or local idiosyncrasies of politics and national governance. One example of this approach is the "train-forward" Neurosurgery Apprenticeship of Madaktari Africa developed at a rural hospital in northern Tanzania, and conducted under a memorandum of understanding with the Tanzanian Ministry of Health and Social Welfare. ${ }^{3}$ Evidence from the Madaktari approach demonstrates its effectiveness in empowering local healthcare providers to safely perform an increasing number of neurosurgical procedures with a decreasing risk of complications. Given the program's success, the Madaktari approach has been promoted by the Tanzanian government as an effective means of closing the gap in neurosurgical care until formal residency training programs produce the neurosurgical workforce density required for the country's population of more than 46 million people. ${ }^{3}$

\section{Creation of a Neurosurgical Residency Program in Haiti}

Prior to 2016, formal training in neurosurgery had not been available in Haiti. Previously, neurosurgical care in Haiti was provided by a combination of infrequent international visits from US-trained neurosurgeons and local Haitian neurosurgeons. Among these, the pediatric neurosurgery program based at the University of Miami was the most successful in creating a sustainable neurosurgical education. Since its inception, the pediatric neurosurgery program has offered assessments for thousands of children and operative care for more than 1000 children since 2003 (Sandoval-Garcia et al: A retrospective review of 401 infants treated for hydrocephalus in Haiti, presented at the AANS/CNS Pediatric Section Meeting, 2017). Although there are limited international training opportunities for Haitian surgeons interested in specializing in neurosurgery, those currently providing care in Haiti have had limited mentored surgical training, and they work with only basic instruments, equipment, and supplies. Access to neurosurgical care in emergency situations such as traumatic brain and spinal injury as well as for congenital disorders, degenerative diseases, and tumors of the nervous system is therefore very limited. The lack of available neurosurgical care, particularly for trauma and congenital anomalies, has posed a significant economic and health burden on Haitian society (estimated at $\$ 4.3$ million USD per year), thereby necessitating the creation of a sustainable neurosurgery residency program (Hubbard et al: Economic benefit of neurosurgical intervention for hydrocephalus in Haiti, presented at the AANS/CNS Pediatric Neurological Surgery Section meeting, 2016).

Over the years, an effort has been made to involve Haitian surgical and pediatric residents in the assessment, operative treatment, and postoperative management of the children at the HBMPM and the state-run hospital. Based on this program, the country's first neurosurgical residency program was forged in 2016 in collaboration with the Haitian Ministry of Health and the medical school of the State University of Haiti (Hôpital de l'Université d'État d'Haiti; HUEH). The program intends to produce one Haitian general surgeon who is fully trained in basic neurosurgery over the course of several years. The overarching goal is to teach fundamental neurosurgical skill sets that are tailored to the needs of the country (neurotrauma, emergency spine surgery, hydrocephalus, basic tumor surgery, etc.).

\section{Hospital Bernard-Mevs/Project Medishare}

Since the 2010 earthquake, the philanthropic organization Project Medishare has continuously supported, staffed, and operated a hospital in Port-au-Prince. Although initially operating out of a field hospital near the airport, Project Medishare moved the hospital to HBMPM, where North American volunteers serve on a rotating basis alongside full-time Haitian staff. The hospital has 10 medical/surgical beds, 6 spinal cord beds, 5 ICU adult beds, and 15 pediatric beds ( 4 neonatal ICU and 4 pediatric ICU). Frequently, volunteers from academic medical centers train Haitian medical, pediatric, and surgical 


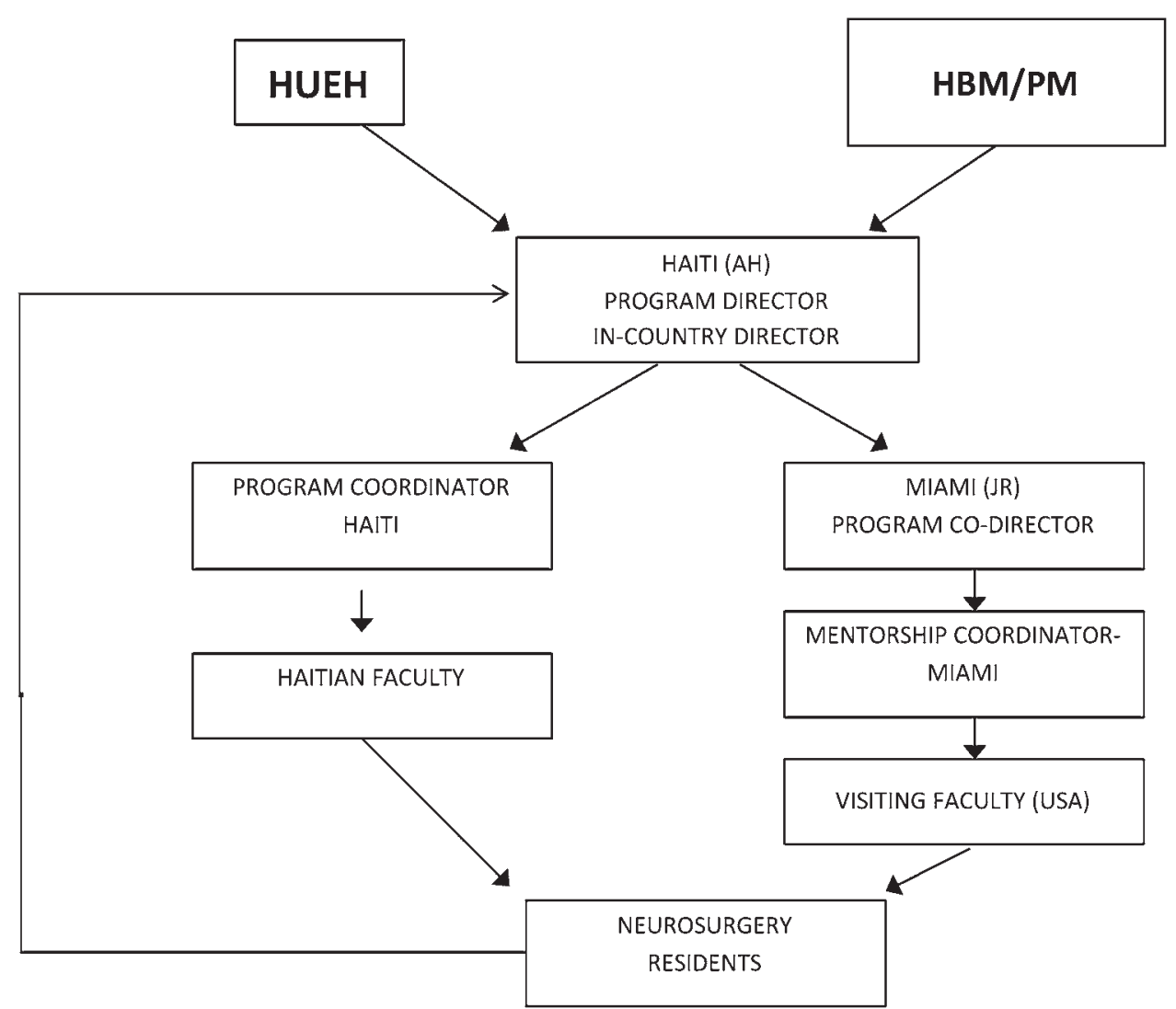

FIG. 1. Chart showing the academic structure of the neurosurgery residency program in Haiti.

residents; medical students; nurses; and allied healthcare providers. In particular, HBMPM features a similar government-sponsored public-private residency program in pediatrics that has helped provide a framework for our current program. Additionally, the presence of neurosurgeons rotating in on a monthly basis creates the unique opportunity to offer training in basic neurosurgery. Given the fact that the state hospital is currently undergoing renovation after the earthquake, HBMPM has become the flagship surgical hospital within Port-au-Prince.

\section{Curriculum}

Given the need for formalized neurosurgical training in Haiti, we have established a curriculum aligned with the goals of the Accreditation Council for Graduate Medical Education International (ACGME-I), with the following objectives: 1) to design a training program that fits the needs of the trainees; 2) to select appropriate training sites to implement the educational activities; 3 ) to provide fiscal and educational support for the fellows; 4) to establish an appropriate academic framework for the implementation of the residency program; and 5) to provide relevant training that targets the endemic neurological pathology with emphasis on limited resources. This program was modeled after the FIENS curriculum, which has been used to foster self-sustaining neurosurgery residency programs in several countries within Central America, Asia, and Africa.

\section{Surgical Training}

The curriculum is geared toward providing neurosurgical training in a wide range of common neurosurgical conditions for which treatment needs are currently unmet (hydrocephalus, congenital disorders, trauma, tumors, and spinal disease). The surgical training is coordinated at 2 major hospitals that are mentioned above: HUEH (undergoing reconstruction) and HBMPM. Surgical training is primarily provided under the direct constant mentorship of the in-country program director (A.H.), and is supplemented by monthly visits from international support teams geared to provide subspecialty training. Subspecialty training from visiting neurosurgeons helps cover basic concepts in the management of the following entities within a resource-limited setting: neurotrauma and critical care, cerebrovascular surgery, neurosurgical oncology, spine surgery, pediatric neurosurgery, surgery of peripheral nervous system, stereotactic/functional neurosurgery, and related disciplines including neurology, neuroradiology, neuropathology, and neuroanesthesiology. With many rotating visiting professors and institutions, a tiered academic mentorship model between both state and private institutions was necessary (Fig. 1). Since the implementation of this model, neurosurgery has become the mainstay surgical specialty at the hospital, with more than 250 cases per year. With direct mentorship, case volume has been steadily increasing at HBMPM. Case volume mainly consists of emergency neurotrauma and pediatric hydroceph- 


\section{A NEUROSURGICAL CASE VOLUME HOSPITAL BERNARD MEVS- PROJECT MEDISHARE}

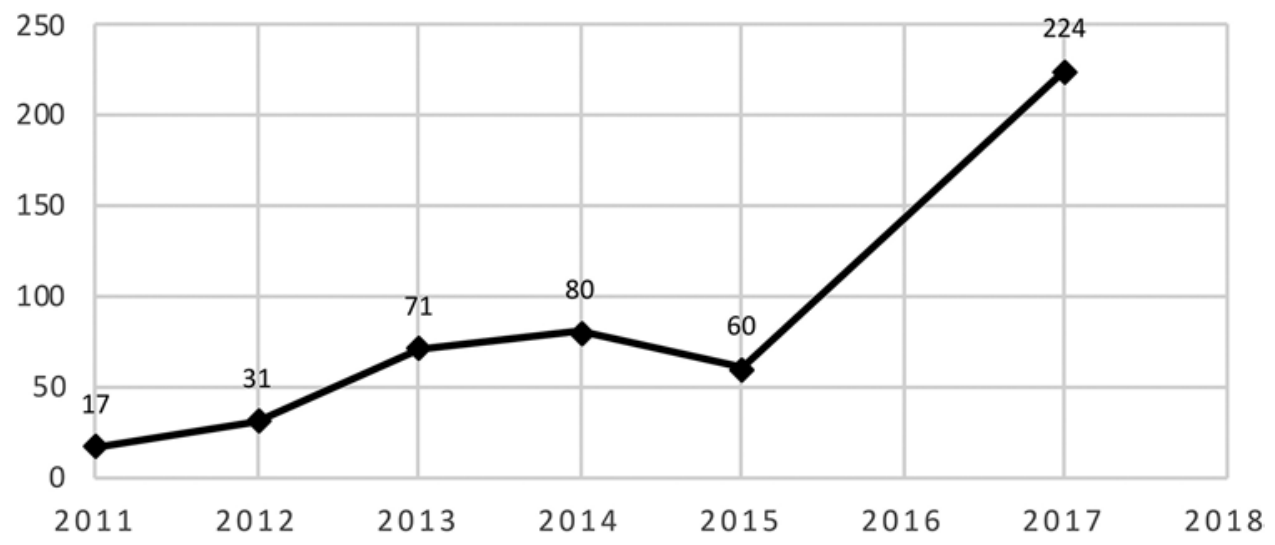

B

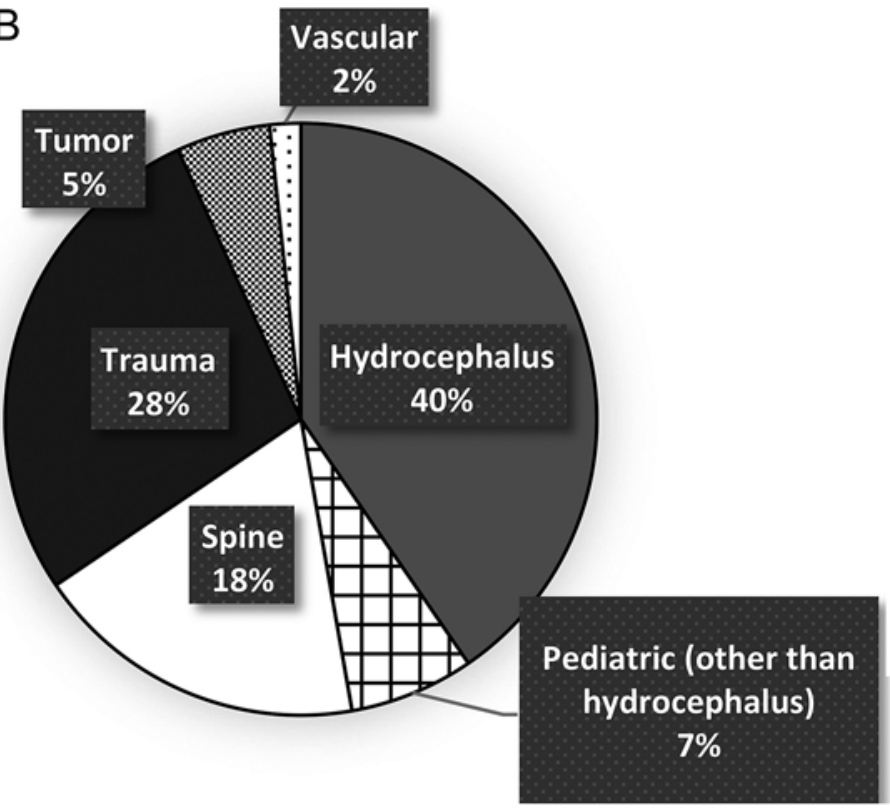

-Hydrocephalus

Q Pediatric (other than hydrocephalus)

uspine

Trauma

ㅈumor

FIG. 2. A: Neurosurgical case volume at HBMPM, by year. B: Subspecialty case breakdown for 1 year of residency program (2016-2017).

alus, mostly due to the current infrastructure and epidemiology of neurological disease within the country (Fig. 2).

\section{Education}

Aside from developing technical skills, core competencies and knowledge base are also reinforced through multiple modalities including web-based learning, conferences, formal didactics, and journal clubs. A web-based open-source learning environment was created using MOODLE (moodlecloud.com, Australia), which pairs basic neurosurgical education modules and weekly online assessments. To bolster neurosurgical education, the resident is assigned reading and/or PowerPoints and brief quizzes on neuroanatomy, neuropathology, neuroradiology, neurology, and neurosurgery (adapted from content assessed by the American Board of Neurological Surgery). Table 2 details the web-based modules and case discussions for the neurosurgical resident. Additionally, when resources and internet are available, the resident is encouraged to participate in teleconferences at the University of Miami including departmental grand rounds, resident journal club, morbidity and mortality conferences, etc. Web-based telemedicine video consultations are also frequently offered through our institution, where the resident can review preoperative imaging and decision-making. Fiscal support (salary for resident and program coordinator) is 
TABLE 2. List of topics covered in neurosurgery online curriculum

\begin{tabular}{c}
\hline Basic courses \\
\hline Neuroanatomy \\
\hline Neurophysiology \\
\hline Neuropathology \\
\hline Neurology \\
\hline Neuroradiology \\
\hline Neuropharmacology \\
\hline Biostatistics \& research methodology \\
\hline Clinical courses \\
\hline Fluid, electrolytes, \& nutrition \\
\hline General critical care \\
\hline Infection \\
\hline Neuroanesthesiology \\
\hline Neurosurgical web-based case discussions \\
\hline Cerebrovascular surgery \\
\hline Neurosurgical oncology \\
\hline Neurotrauma \& neurosurgical critical care \\
\hline Pain management \\
\hline Pediatric neurosurgery \\
\hline Surgery of the peripheral nervous system \\
\hline Spine surgery \\
\hline Stereotactic \& functional neurosurgery \\
\hline
\end{tabular}

provided through a nonprofit organization (Haiti Healthy Kids, Miami, FL), and resident educational supplies including textbooks, surgical loupes, etc., are largely provided by our institution.

\section{Expected Results}

This initiative would allow Haiti to graduate a fully trained neurosurgeon by the end of the 3-4 years of the program and then annually thereafter. This assumes that 1 new trainee will be added each year and, by year 3, there will be a maximum of 3 residents training at HBMPM. Certification of completion will be granted once the resident has met all of the clinical milestones set forth by the clinical competency committee; each resident is evaluated by faculty members during site visits to assess his/her safety, technical skills, and intraoperative decision-making. Additionally, at the end of residency, each resident is expected to complete written and oral examinations (modeled after the written and oral board examinations given by the American Board of Neurological Surgeons). After completion of these requirements set forth in our curriculum, terminal certification will be jointly granted by the National University, Haitian Ministry of Health, and HBMPM. Once the first few neurosurgeons are trained, the former trainees will continue to train and educate future residents/fellows, expanding the neurosurgical training into other urban centers throughout Haiti (e.g., Hinche, Mirebalais, Cap Haitien). Concomitant initiatives to develop structured and adapted neurosurgical units in the regional hospitals in these major population centers across the country will be prioritized as the expertise becomes available. We expect that access of the communities to appropriate neurosurgical care will increase significantly with implementation of this program and that thousands of patients will benefit from this much-needed service over the next $10-20$ years.

\section{Conclusions}

Although in its infancy, this neurosurgery residency has remarkable potential to develop capacity building within Haiti over the course of several years. However, several limitations including lack of infrastructure, foreign dependency, and fiscal restraints continue to encumber training in Haiti and other LMICs. Nevertheless, with time, reliance on visiting neurosurgeons will subside and a continuous and nurturing training environment may be fostered. Despite the long, arduous path toward sustainable neurosurgery training in Haiti, the innumerable benefits of this program will undoubtedly fortify the Haitian healthcare system within the next few years.

\section{References}

1. Barthélemy EJ, Benjamin E, Edouard Jean-Pierre MY, Poitevien $\mathrm{G}$, Ernst $\mathrm{S}$, Osborn I, et al: A prospective emergency department-based study of pattern and outcome of neurologic and neurosurgical diseases in Haiti. World Neurosurg 82:948-953, 2014

2. Centers for Disease Control and Prevention: Post-earthquake injuries treated at a field hospital --- Haiti, 2010. MMWR

Morb Mortal Wkly Rep 59:1673-1677, 2011

3. Ellegala DB, Simpson L, Mayegga E, Nuwas E, Samo H, Naman N, et al: Neurosurgical capacity building in the developing world through focused training. J Neurosurg 121:15261532,2014

4. Farmer PE, Kim JY: Surgery and global health: a view from beyond the OR. World J Surg 32:533-536, 2008

5. Ferreira S: Cholera threatens Haiti after Hurricane Matthew. BMJ 355:i5516, 2016

6. Groen RS, Samai M, Stewart KA, Cassidy LD, Kamara TB, Yambasu SE, et al: Untreated surgical conditions in Sierra Leone: a cluster randomised, cross-sectional, countrywide survey. Lancet 380:1082-1087, 2012

7. Haglund MM, Warf B, Fuller A, Freischlag K, Muhumuza $\mathrm{M}$, Ssenyonjo H, et al: Past, present, and future of neurosurgery in Uganda. Neurosurgery 80:656-661, 2017

8. Meara JG, Greenberg SL: The Lancet Commission on Global Surgery. Global surgery 2030: Evidence and solutions for achieving health, welfare and economic development. Surgery 157:834-835, 2015

9. Park KB, Johnson WD, Dempsey RJ: Global neurosurgery: the unmet need. World Neurosurg 88:32-35, 2016

10. Shrime MG, Bickler SW, Alkire BC, Mock C: Global burden of surgical disease: an estimation from the provider perspective. Lancet Glob Health 3 (Suppl 2):S8-S9, 2015

11. Stewart B, Khanduri P, McCord C, Ohene-Yeboah M, Uranues S, Vega Rivera F, et al: Global disease burden of conditions requiring emergency surgery. Br J Surg 101:e9-e22, 2014

12. Vashisth N: Roadway safety assessment and test application of iRAP along National Highway 3 in Haiti [thesis]. Clemson, SC: Clemson University, 2016

13. Warf BC: Educate one to save a few. Educate a few to save many. World Neurosurg 79 (2 Suppl):15.e15-15.e18, 2013

14. Xu LW, Vaca SD, Nalwanga J, Muhumuza C, Vail D, Lerman BJ, et al: Life after the neurosurgical ward in Sub-Saharan 
Africa: neurosurgical treatment and outpatient outcomes in Uganda. World Neurosurg 113:e153-e160, 2018

15. Zuraik C, Sampalis J: Epidemiology of traumatic injuries at an urban hospital in Port-au-Prince, Haiti. World J Surg 41:2674-2680, 2017

\section{Disclosures}

The authors report no conflict of interest concerning the materials or methods used in this study or the findings specified in this paper.

\section{Author Contributions}

Conception and design: Ragheb, Shah. Acquisition of data: Shah, Barthélemy, LaFortune, Gernsback. Analysis and interpretation of data: Shah, LaFortune. Drafting the article: Ragheb, Shah, Barthélemy. Critically revising the article: Ragheb, Shah, Barthélemy, Gernsback. Reviewed submitted version of manuscript: Shah, Barthélemy, LaFortune, Gernsback, Henry. Administrative/ technical/material support: Ragheb, LaFortune, Henry, Green. Study supervision: Ragheb, Henry, Green.

\section{Supplemental Information \\ Videos}

Video Abstract. https://vimeo.com/288345192.

\section{Correspondence}

John Ragheb: University of Miami, Miami, FL.jragheb@med. miami.edu. 